\title{
Avaliação participativa da qualidade do solo como proposta de construção do conhecimento agroecológico em um agroecossistema familiar
}

\author{
David Marx Antunes de Melo ${ }^{1}$; Wedson Aleff Oliveira da Silva ${ }^{2}$; Gerson João da Silva ${ }^{3}$; Eduarda Fernandes dos Reis ${ }^{4}$; \\ Gabriel Torres Rodrigues ; Alexandre Eduardo de Araújo 6
}

Universidade Federal da Paraíba; ${ }^{1}$ davidatunes@gmail.com; ${ }^{2}$ wedsonaleff@gmail.com; ${ }^{3}$ gersonjoaoajoao2@gmail.com; imbujurema@gmail.com; ${ }^{4}$ gabriel.agroeco@gmail.com; ${ }^{6}$ alexandreeduardodearaujo@ hotmail.com.

\begin{abstract}
RESUMO: O manejo dos agroecossistemas pode acarretar impactos no solo. Partindo da ideia que os agricultores familiares detêm muito conhecimento sobre a biodiversidade dos agroecossistemas e dos solos. A avaliação dos indicadores de qualidade do solo realizada juntamente com as famílias dos agricultores têm demonstrado que essa é uma opção viável no processo de transição agroecológica em busca de sistemas de produção cada vez mais sustentáveis. Nessa perspectiva, o objetivo com o presente trabalho foi realizar avaliações participativas através de indicadores da qualidade do solo de um agroecossistema em transição agroecológica. Para tal, foram escolhidos oito indicadores, sendo eles: declividade; estrutura; compactação; erosão; cobertura vegetal; cor; atividade biológica e matéria orgânica, sendo utilizados em quatro subsistemas agrícolas: pasto, roçado, quintal produtivo e mata. Foi realizada uma abordagem descritiva das médias dos tratamentos. Quanto aos resultados, todos os subsistemas apresentaram valores satisfatórios, especificamente os subsistemas quintal produtivo e o roçado, requerendo atenção para o subsistema pasto, o qual apresentou menores índices de sustentabilidade. O método utilizado mostrou-se eficiente, enquanto trabalhado participativamente com as famílias agricultoras, na avaliação da sustentabilidade e qualidade de seus solos.
\end{abstract}

PALAVRAS-CHAVE: Agroecologia; Indicadores de sustentabilidade; Metodologias participativas.

\section{INTRODUÇÃO}

O solo é um recurso natural vivo e dinâmico que condiciona e sustenta a produção de alimentos, fibras e regula o balanço global do ecossistema. Principalmente, quando se trata de agroecossistemas de base familiar, no qual o solo é visto não apenas como um meio de produção, mas também como um componente holístico do sistema que influencia inúmeras relações e interações de diversos organismos, criando um enfoque para o solo com essa teia de relações, de complexidade (FIALHO, 2005; CAPORAL, 2009).

O conceito de agroecossistema, compreendido como um ecossistema onde o fluxo de energia e nutrientes é, através da prática agrícola, direcionado para a produção de alimentos, fibras e demais produtos, remete a uma condição estrutural e sistêmica de análise que permite abordar a produção agropecuária de forma holística, incluindo os conjuntos complexos de insumos e produção, bem como identificar as interconexões existentes entre as partes componentes (SARANDÓN, 2014).

Deste modo, sabe-se que todo e qualquer agroecossistema manejado acarreta impactos ao solo, desde sua estrutura, características físicas, atividade biológica e sua composição química. A partir deste entendimento, o uso de indicadores para avaliação dos solos é de fundamental importância no sentido de que a partir de sua interpretação é possível estabelecer práticas conservacionistas voltadas especificamente para o resultado do diagnóstico. Neste sentido, torna-se necessária a realização de estudos e pesquisas voltadas para os indicadores de qualidade do solo, que levem em consideração os aspectos da sustentabilidade dos sistemas de produção, visto que a agricultura é a base fundamental para uma sociedade sustentável (CARLESI, 2008).

Segundo Araújo (2007), a qualidade do solo é definida como a capacidade de sustentar no ecossistema ecológico sua produtividade biológica, manutenção da qualidade ambiental e promoção da saúde das plantas e animais, podendo ser avaliada com o uso de indicadores físicos, químicos e biológicos.

Nos processos de avaliação e de monitoramento da qualidade do solo ressalta-se que os agricultores detêm muito conhecimento sobre do solo e da biodiversidade dos agroecossistemas e que esses conhecimentos precisam ser considerados na avaliação e manejo dos solos, pois, são poucos os estudos que incorporam esses conhecimentos (CARDOSO; FAVERO, 2018). De acordo com Altieri e Nicholls (2002) os conhecimentos locais e tradicionais são importantes para a compreensão da dinâmica de funcionamento de um agroecossistema. A construção do saber de agricultores, relativo ao solo, vem sendo constituído pelo convívio de longos anos com a atividade agrícola e possibilita que o sujeito interaja como peça fundamental na construção da ciência do solo e da Agroecologia (AUDEH et al., 2011).

Dentre os instrumentos de indicadores de qualidade do solo, diferentes métodos visuais de avaliação da qualidade do solo podem ser realizados no campo juntamente com os agricultores (BATEY; MCKENZIE, 2006). Estas avaliações apresentam proveitos por serem rápidas, de baixo custo e por viabilizar o diagnóstico da qualidade do solo 
MELO, D. M. A. et al. Avaliação participativa da qualidade do solo como proposta de construção do conhecimento agroecológico em um agroecossistema familiar. In: II Congresso Paraibano de Agroecologia \& IV Exposição Tecnológica, 2019. Anais... Caderno Verde de Agroecologia e Desenvolvimento Sustentável, Pombal, v. 9, n.7, e-7065, 2019.

(CARVALHO, 2009). Esta análise em campo com a participação dos agricultores é uma estratégia para o planejamento agrícola, aprimorando os sistemas de manejo com características de alta produtividade e preservação ambiental.

Desse modo, o objetivo com este trabalho foi avaliar através de métodos participativos indicadores da qualidade do solo de um agroecossistema em transição agroecológica.

\section{MATERIAL E MÉTODOS}

A pesquisa foi realizada no município de Solânea - PB, especificamente, no sítio Juazeirinho Latitude. 647'11.41"S, Longitude. 3540'53.53"O, em um agroecossistema de base familiar em processo transição agroecológica avançada, integrante do Sindicato dos Trabalhadores Rurais de Solânea. O município de Solânea possui clima tropical semiárido, subúmido seco e floresta estacional semidecidual. O solo do agroecossistema foi classificado como Neossolo Regolítico com textura média, de acordo com o Sistema Brasileiro de Classificação de Solos - SiBCS (EMBRAPA, 2013).

De acordo com Verdejo (2006), foi realizada uma travessia de reconhecimento da unidade juntamente com a família agricultora, na qual realizou-se o uso dos indicadores de avaliação da qualidade do solo adaptado de Nicholls et al. (2004) e Primavesi (2016), onde foi desenvolvido para avaliar, participativamente, formas mais acessíveis de caracterização da qualidade do solo em diferentes sistemas incentivando a construção do conhecimento agroecológico de famílias agricultoras e demais sujeitos envolvidos.

Metodologicamente foram utilizados oitos indicadores, tais como: declividade; estrutura; compactação; cobertura; erosão; cor; atividade biológica e matéria orgânica, sendo vivenciado em quatro subsistemas agrícolas identificados no mapa a seguir:

Figura 1: Área total e subsistemas do agroecossistema Juazeirinho em Solânea - PB.

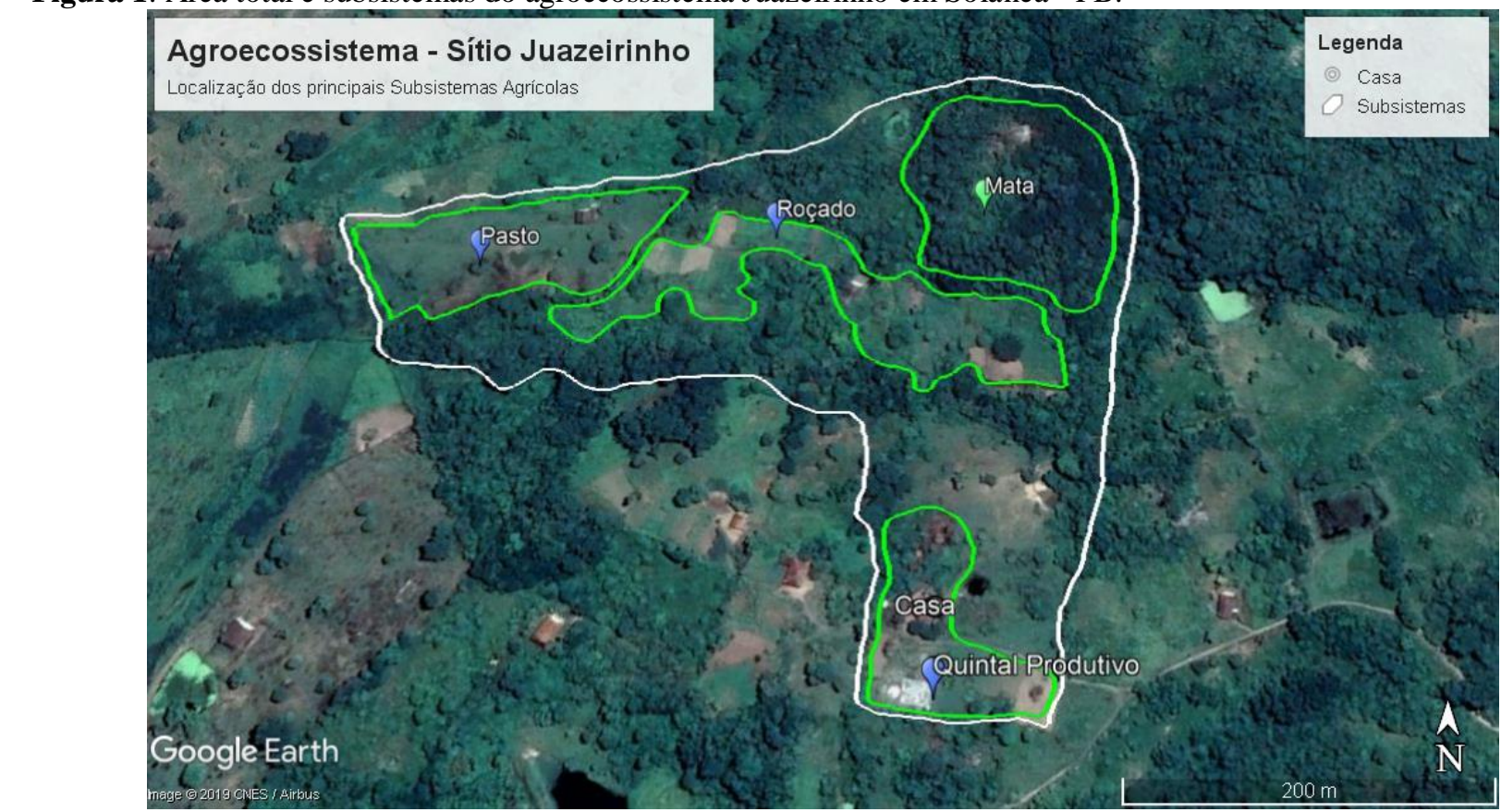

Fonte: Melo (2019).

A área total do Agroecossistema é de 10,7 hectares (Ha), compreendendo principalmente quatro subsistemas. O subsistema quintal produtivo possui $0,7 \mathrm{Ha}$ e é o local onde são cultivadas principalmente hortaliças e frutíferas destinadas ao consumo familiar e comercialização direta na feira Agroecológica do município. No subsistema roçado, que compreende uma área de 1,4 Ha, a principal atividade é o cultivo tradicional de espécies como: macaxeira, batata-doce, fava, feijão, milho, jerimum, dentre outras culturas em manejo de consórcio de espécies e rotação de culturas. O subsistema mata possui 1,7 Ha e é responsável pelos serviços ecossistêmicos locais como a manutenção da biodiversidade e a ciclagem de nutrientes além de ser elemento essencial para a conservação dos recursos hídricos locais. O subsistema pasto, de 1,2 ha é composto basicamente por brachiaria e algumas espécies espontâneas nativas que são utilizadas para alimentação animal.

Para a realização da avaliação em campo junto com os agricultores foi a aplicado um questionário qualitativo adaptado de Nicholls et al. (2004), desenvolvido para avaliar, juntamente com os agricultores familiares, formas mais acessíveis de avaliar a qualidade do solo em diferentes sistemas. Para esse método foram usados sete variáveis que possuem seus devidos critérios de escolhas, quais sejam: Declividade, de acordo com Machado (2006) que traz formas de avaliação do relevo juntamente com o agricultor favorecendo o mesmo uma sua percepção da paisagem agrícola no 
MELO, D. M. A. et al. Avaliação participativa da qualidade do solo como proposta de construção do conhecimento agroecológico em um agroecossistema familiar. In: II Congresso Paraibano de Agroecologia \& IV Exposição Tecnológica, 2019. Anais... Caderno Verde de Agroecologia e Desenvolvimento Sustentável, Pombal, v. 9, n.7, e-7065, 2019.

agroecossistema. Estrutura, avaliou-se observando sua estrutura física das partículas e agregados, se os solos encontramse empoados, desagregando-se com facilidade, sem agregados visíveis; se solos possuem mínima capacidade de uma estrutura granular das partículas do solo, cujos agregados são facilmente quebrados sob pressão suave dos dedos; (NICHOLLS et al., 2004; PRIMAVESI, 2016). O teste de Compactação foi realizado a partir da penetração vertical de um penetrômetro em diferentes pontos das áreas e registrando os níveis de sua penetração (NICHOLLS et al., 2004). Cobertura do solo foi observada a condição atual da cobertura viva ou morta dos solos dos agroecossistemas, sendo visualizada a olho nu in locu, tendo como parâmetro não desejável o solo exposto; menos de 50\% do solo coberto por resíduos ou cobertura viva; e mais de $50 \%$ do solo coberto por resíduos ou cobertura viva (NICHOLLS et al., 2004). Erosão, se houve sinais de ravinas, valas ou crateras nos solos dos agroecossistemas. Cor do solo esse indicador foi avaliado após a coleta das amostras dos solos onde os investigadores visualizaram a olho nu, a coloração dos solos, onde o primeiro valor menos desejável remete a um solo pálido com odor indesejável; em seguida um solo de cor marrom claro e sem odor; e cor marrom escuro e odor de matéria fresca (NICHOLLS et al., 2004). Presença de invertebrados, foi realizada a observação no momento em que coletou-se as amostras de cada área, onde pode ser avaliado a partir da ausência de atividade de invertebrados; poucas minhocas e artrópodes presentes; e presença abundante de organismos invertebrados (adaptado de NICHOLLS et al., 2004). Atividade biológica foi realizada utilizando o peróxido de hidrogênio volume 10 e as amostras de solo de cada agroecossistema onde o peróxido reagiu com às membranas dos microrganismos e o carbono do solo, liberando gás carbônico $\left(\mathrm{CO}_{2}\right)$ causando efervescência nas amostras (adaptado de BORGES et al., 2013).

Nesse método as avaliações foram expressas na forma de escores entre os menores e os maiores níveis relativos em uma escala de 1 (baixo), 2 (baixo-médio), 3 (médio), 4 (médio-alto) e 5 (alto), sendo seguido critérios para às diferentes categorias (NICHOLLS et al., 2015). A Análise de determinação da matéria orgânica foi realizada em forma de triplicata no laboratório de solos da UFPB-CCHSA, de acordo com os procedimentos da Embrapa (2011).

Foi realizada uma abordagem descritiva das médias geral de qualidade do solo de quatro tratamentos, oito variáveis e três repetições.

Foram utilizadas nesse método uma abordagem descritiva das médias geral de qualidade do solo de quatro tratamentos, oito variáveis e três repetições.

\section{RESULTADOS E DISCUSSÃO}

Com base nos resultados apresentados na figura 1, observa-se os valores médios dos indicadores de qualidade do solo nos subsistemas pasto, roçado, quintal produtivo e mata.

Figura 2: Valores médios referentes aos subsistemas analisados no sítio Juazeirinho em Solânea - PB.

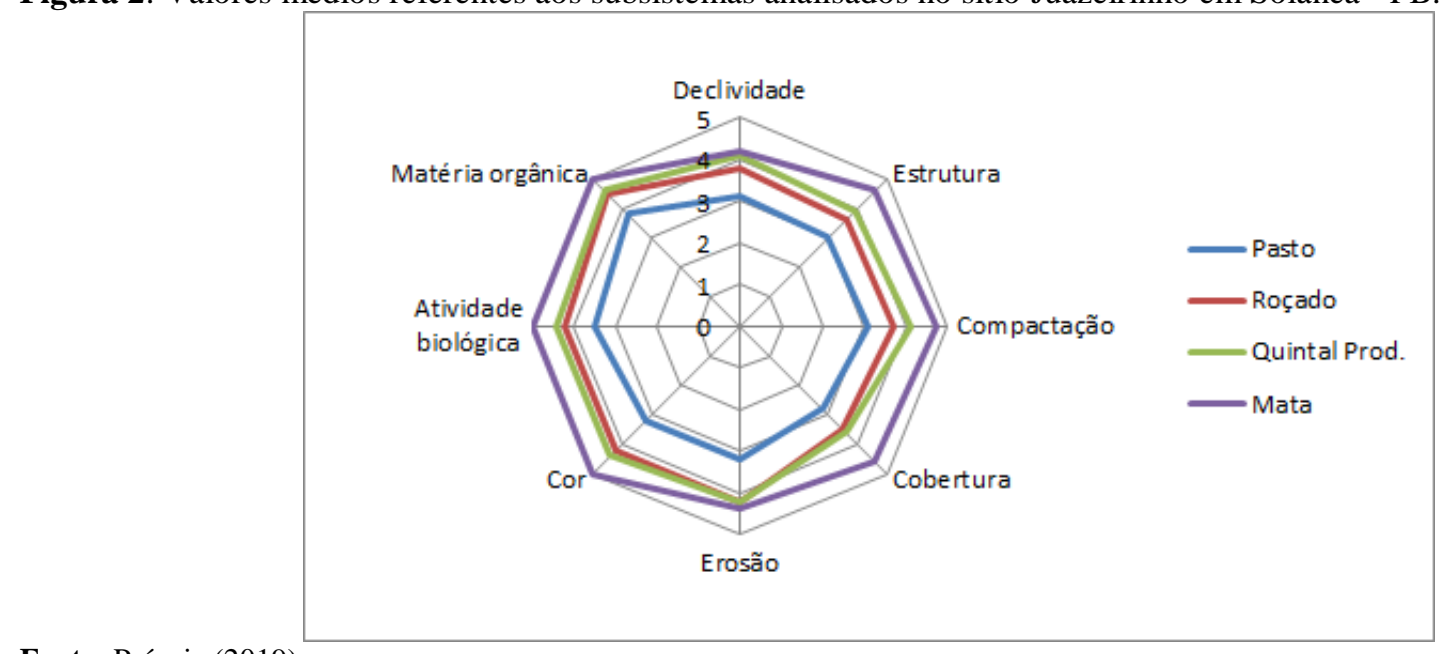

Fonte: Própria (2019)

Geograficamente o agroecossistema está localizado em relevo ondulado de serra, desse modo, para o indicador de declividade, os subsistemas mata e quintal produtivo apresentaram melhores resultados quanto à sustentabilidade, com valores de 4,2 e 4,1, respectivamente, por estarem localizados em um perímetro mais baixo, o que promove a ocorrência de maior deposição de sedimentos, gerando boa fertilidade ao solo. Dentre os outros subsistemas, roçado e pasto apresentaram menores valores 3,8 e 3,1, respectivamente, por estarem situados em uma localidade mais íngreme, requerendo maior atenção no manejo e manutenção destes solos, buscando a adesão de técnicas de contenção em curvas de nível que podem reduzir os fluxos hídricos, controlando assim, a lixiviação dos nutrientes no solo e os sinais erosivos (PEREZ-MARIN et al., 2015). Os agricultores interpretam este indicador através das diferenciações do relevo presente em cada subsistema. 
MELO, D. M. A. et al. Avaliação participativa da qualidade do solo como proposta de construção do conhecimento agroecológico em um agroecossistema familiar. In: II Congresso Paraibano de Agroecologia \& IV Exposição Tecnológica, 2019. Anais... Caderno Verde de Agroecologia e Desenvolvimento Sustentável, Pombal, v. 9, n.7, e-7065, 2019.

Para avaliação dos indicadores físicos, estrutura e compactação, a mata apresenta melhores valores, 4,6 e 4,7, respectivamente. Estes indicadores representam o nível de sustentabilidade deste ecossistema, por estar mais tempo sem nenhum revolvimento, justificando ser considerada a área referência para os outros subsistemas. Os agricultores interpretam este indicador através da diferenciação visual da estrutura de cada solo, como também por meio do teste do ferro a qual é utilizado para medir a compactação. Ainda sobre os parâmetros físicos, o subsistema Roçado e Quintal Produtivo apresentaram valores próximos, considerados médios-altos de acordo com as categorias de avaliação. O subsistema pasto apresentou valores mais baixos comparado aos outros subsistemas analisados, com índices de 3 e 3,1 respectivos (estrutura e compactação). Este fator representa a baixa diversidade de espécies, o que impossibilita uma boa agregação das partículas do solo e, consequentemente, problemas na infiltração, retenção de água e aeração. Manejos para melhoria da qualidade dos indicadores estrutura e compactação do subsistema pasto são recomendados.

De acordo com Primavesi (2016), a cobertura do solo, seja viva ou morta, é um indicador de grande importância para manutenção da fertilidade do solo, como também na proteção do sistema macroporoso, evitando erosões generalizadas e garantindo uma boa retenção de água. Este parâmetro é visto pelos agricultores como a camada superficial de matéria orgânica presente nos solos.

Os valores apresentados neste indicador, apontam a mata como unidade referência atingindo índices médio-alto $(4,6)$, por se encontrar em estabilidade ecológica, exibindo, dessa forma, maior parte do seu solo coberto. Os subsistemas do cultivo de batata (Ipomoea batatas) e quintal produtivo apresentaram valores médios de acordo com a classificação 3,5 e 3,6, respectivamente, requerendo a adoção práticas conservacionais que aumentem a cobertura destes solos. A área de pastagem, apresentou menor índice $(2,8)$, considerado baixo-médio de acordo com a classificação estabelecida na metodologia, este indicador demanda uma maior atenção para esta variável, buscando a adoção de práticas que aumentem a cobertura vegetal.

No indicador erosão, os subsistemas mata, roçado e quintal produtivo apresentaram valores considerados médioalto, com valores respectivos (4,4, 4,2 e 4,2). Esses agroecossistemas possuem baixas declividades e estratégias de controle de erosão, como curva de nível e boa presença de cobertura vegetal adotada pelos agricultores. O subsistema da área de pastagem apresentou valor médio (3,2), devido a declividade do terreno e pouca presença de cobertura vegetal, coincidindo uma maior erosão do terreno. A erosão hídrica, principal forma de degradação dos solos, é resultante da ação conjunta do impacto das gotas de chuva e da enxurrada com a declividade que, além de partículas de solo, transporta nutrientes, matéria orgânica, causando prejuízos à atividade agrícola (BERTOL et al., 2007).

O indicador de cor representa uma característica muito importante, onde cores mais escuras geralmente são atribuídas a solos mais férteis por causa da presença de húmus, no entanto, nem todos os solos de cor escura indicam solo fértil ou humoso. A família já utiliza esse indicador para analisar a qualidade de seus solos. Solos de cores escuras em estado úmido e cinzento em estado seco são considerados solos sem matéria orgânica (PRIMAVESI; PRIMAVESI, 2018).

Para avaliação deste indicador relacionado aos subsistemas analisados, a mata apresentou valor alto de acordo com os parâmetros estabelecidos (5), apontado coloração escura (húmus), por efeito da matéria orgânica no solo. Os agroecossistemas de roçado e quintal produtivo, apresentaram valores semelhantes (4,2 e 4,4, respectivamente), considerados médio-alto, ambos apresentam características semelhantes devido estarem localizados em relevo mais baixo e possuírem tratos culturais parecidos. O subsistema pasto possui menor índice de acordo com a escala estabelecida, com valor equivalente a 3,5 considerado médio. Esta interpretação relaciona-se pela baixa quantidade de cobertura e matéria orgânica presente nesse solo, ocasionadas devido seus problemas erosivos.

A atividade biológica do solo foi medida através do teste de efervescência, apontando boa reação da oxidação do peróxido para o ecossistema mata, que por sua diversidade microbiológica apresentou valor equivalente a 5, considerado alto na escala, representado seu equilíbrio enquanto ecossistema sustentável. Os subsistemas quintal produtivo e roçado apresentaram valores de 4,4 e 4,2, respectivamente, considerados médio-alto de acordo com a escala, devido a assistência prestada a estes subsistemas no quesito de garantir um solo ideal para produção, subsistência e comercialização dos produtos ali cultivados. A área de pasto, como observado na Figura 1, apresentou menor índice de atividade biológica de acordo com os valores obtidos e o gráfico apresentado, apresentando valor médio de acordo com a escala, sendo ele 3,9. Este fator é consequência da falta de cobertura e matéria orgânica, na composição do mesmo, ocasionando pouca efervescência no teste aderido.

A presença de matéria orgânica também é considerada um indicador da qualidade do solo indispensável para manutenção da vida e da saúde do solo. Nesta variável, o ecossistema mata apresenta valor equivalente a 5, considerado alto, representando o ideal de sustentabilidade deste agroecossistema. Os subsistemas quintal produtivo e roçado, novamente apresentaram valores semelhantes, 4,6 e 4,5, respectivamente, valor considerado como categoria média-alta, devido às práticas de manejo adotadas pelos agricultores familiares nestes agroecossistemas, como o cultivo de plantas leguminosas, adição de estercos bovinos e permanência dos resíduos vegetais na camada superficial. Enquanto o subsistema pasto apresentou menor valor (4) para este indicador, no entanto, ainda encontra-se na categoria média-alta.

De acordo com Primavesi (2016), a matéria orgânica não é adubo, ela é alimento para vida aeróbia do solo, que o agrega, criando o sistema macroporoso por onde entram ar e água indispensáveis para a produção vegetal, considerado elemento primordial para manutenção da vida do solo e reserva de recursos hídricos e nutricionais.

A utilização da Figura do tipo radar para representação visual dos indicadores demonstra o êxito da ferramenta metodológica, uma vez que apresentou ser um método simples e eficiente, que valoriza e incorpora os saberes locais dos 
MELO, D. M. A. et al. Avaliação participativa da qualidade do solo como proposta de construção do conhecimento agroecológico em um agroecossistema familiar. In: II Congresso Paraibano de Agroecologia \& IV Exposição Tecnológica, 2019. Anais... Caderno Verde de Agroecologia e Desenvolvimento Sustentável, Pombal, v. 9, n.7, e-7065, 2019.

agricultores familiares. Altieri e Nicholls (2002) ainda reforçam que este tipo de Figura, além de permitir aos agricultores visualizarem suas práticas pela representação visual de seus indicadores, permite também observar quais aspectos estão mais debilitados e quais precisam ser priorizados.

Os agricultores familiares em questão possuem saberes e vivências únicas em relação ao manejo dos seus agroecossistemas, dos seus solos, o que denota um empoderamento de si em seus contextos sociais e culturais, criando assim, alto potencial de definição e consolidação de métodos de análise da qualidade do solo, como esse utilizado no presente trabalho. Todo o processo de construção participante e aplicação do método reforçou a percepção do solo como um componente vivo da paisagem, o que traz a possibilidade de melhores condições de planejamento na busca da sustentabilidade do agroecossistema e solução dos seus próprios desafios.

\section{CONCLUSÕES}

Todos os subsistemas obtiveram valores de nível médio a médio-alto, o que demonstra uma boa qualidade da saúde dos solos e, consequentemente, dos agroecossistemas. O subsistema mata logrou a melhor índice médio geral $(4,6)$, o subsistema quintal produtivo ficou com $(4,1)$, o subsistema roçado alcançou $(3,9)$ e, por fim, o Pasto obteve $(3,2)$ para o estudo realizado, demonstrado no geral ótimos resultados, uma vez que são orientados pelo enfoque da Agroecologia, tendo em vista a otimização produtiva e avanço no tempo e espaço na transição agroecológica.

\section{REFERÊNCIAS}

ALTIERI, M., NICHOLLS, C. I. Sistema agroecológico rápido de evaluación de calidad de suelo y salud de cultivos en el agroecosistema de café. In: Un método agroecológico rápido para la evaluación de la sostenibilidad de cafetales. Manejo Integrado de Praga.

ARAÚJO, Ademir Sérgio Ferreira; MONTEIRO, Regina Teresa Rosim. Indicadores biológicos de qualidade do solo. Bioscience Journal, v. 23, n. 3, 2007.

AUDEH, S. J. S.; LIMA, A. C. R.; CARDOSO, I. M.; CASALINHO, H. D.; JUCKSCH, I. J. Qualidade do solo: uma visão etnopedológica em propriedades agrícolas familiares produtoras de fumo orgânico. Rev. Bras. de Agroecologia. 34-48, 2011.

BATEY, T.; MCKENZIE, D. C. Soil compaction: identification directly in the field. Soil Use and Management, v. 22, n. 2, p. 123-131, 2006.

BERTOL, I.; COGO, N. P.; SCHICK, J.; GUDAGNIN, J. C.; AMARAL, A. J. Aspectos financeiros relacionados às perdas de nutrientes por erosão hídrica em diferentes sistemas de manejo do solo. Revista Brasileira de Ciência do Solo, v. 31, n. 1, p. 133-142, 2007.

BORGES, P. H. C. et al. Peróxido de Hidrogênio na Determinação dos Teores de Carbono Orgânico do Solo - uma Alternativa Simples e de Menor Impacto Ambiental. In: CONGRESSO BRASILEIRO DE AGROECOLOGIA, Porto Alegre. Trabalho científico. Viçosa: Cadernos de Agroecologia, V. 8, p. 2 - 8. 2013.

CAPORAL, Francisco Roberto et al. Agroecologia: uma nova ciência para apoiar a transição a agriculturas mais sustentáveis. Brasília: MDA/SAF, 2009.

CARDOSO, I. M.; FÁVERO, C. Solos e agroecologia. (Coleção transição agroecológica). V. 4. Brasília, DF: Embrapa, 373 p. 2018.

CARLESI, Sebastián Elola et al. Construção participativa de indicadores de qualidade do solo para avaliação da sustentabilidade de unidades olerícolas no sul do Uruguai. 2008.

CARVALHO, Tiago Correia Martins. Metodologia de avaliação de alternativas de gestão dos carvalhais baseada nos produtos e serviços do ecossistema: aplicação no parque natural do Alvão. 2009. Tese de Doutorado. FCT-UNL.

FIALHO, JAMILI SILVA. Indicadores da qualidade do solo em sistemas agrícolas anuais e perenes na Chapada do Apodi-Ceará. 2005.

SOLOS, Embrapa. Sistema brasileiro de classificação de solos. Centro Nacional de Pesquisa de Solos: Rio de Janeiro, 2013. 
MELO, D. M. A. et al. Avaliação participativa da qualidade do solo como proposta de construção do conhecimento agroecológico em um agroecossistema familiar. In: II Congresso Paraibano de Agroecologia \& IV Exposição Tecnológica, 2019. Anais... Caderno Verde de Agroecologia e Desenvolvimento Sustentável, Pombal, v. 9, n.7, e-7065, 2019.

MACHADO, C.T.T. ; MACHADO, A.T.. Roteiro de diagnóstico participativo de agroecossistemas: Proposta para avaliações com enfoque na agrobiodiversidade e em práticas agroecológicas. Planaltina: Embrapa Cerrados, documentos. 58 p. 2006.

NICHOLLS, C. I.; ALTIERI, M. A.; DEZANET, A.; LANA, M.; FEISTAUER, D.; OURIQUES, M. A rapid farmerfriendly agroecological method to estimate soil quality and crop health in vineyard systems. Biodynamics, Pottstow, n. 250, p. 33-40, 2004

NICHOLLS, C. I.; ALTIERI, M.; SALAZAR, A. H.; LANA, M. Agroecologia e o desenho de sistemas agrícolas resilientes às mudanças climáticas. Revista Agriculturas, n. 2. Rio de Janeiro. Janeiro de 2015.

PEREZ-MARIN A. M.; VASCONCELOS, V. A.; MEDEIROS, S. S.; TINOCO, L. B. M.; MOREIRA, J. M.; ULLOA, L. F. Manual metodológico: práticas mecânicas, físicas e biotecnológicas de manejo e recuperação de áreas degradadas em condições semiáridas. Campina Grande: INSA, 58p. 2015.

PRIMAVESI, A. M.. Manual do solo vivo. São Paulo: Expressão Popular, 2016.

PRIMAVESI, A. M.; PRIMAVESI, A. A biocenose do solo na produção vegetal \& Deficiências minerais em culturas: nutrição e produção vegetal. São Paulo: Expressão Popular, 2018.

SARANDÓN, S. J. El agroecosistema: Un ecosistema modificado. In: SARANDÓN, S. J.; FLORES, C. C. (Coord.). Agroecología: bases teóricas para el diseño y manejo de agroecosistemas sustentables. La Plata - Argentina: Universidad Nacional de La Plata, p: 100-130. 2014.

VERDEJO, Miguel Expósito. Diagnóstico rural participativo DRP: guia prático. Brasília: Ministério do, 2006.

\section{AGRADECIMENTOS}

Apoio financeiro: Fundação de Apoio à Pesquisa do Estado da Paraíba - FAPESQ. 